\title{
ANÁLISE ENERGÉTICA NA PRODUÇÃO DE FENO DE Cynodon dactylon (L.) PERS ${ }^{1}$
}

\section{ALESSANDRO T. CAMPOS ${ }^{2}$, JOSÉ R. C. SAGLIETTI ${ }^{3}$, ALOÍSIO T. CAMPOS ${ }^{4}$, OSMAR C. BUENO}

RESUMO: O objetivo do trabalho foi caracterizar o consumo de energia na implantação, condução, fenação e armazenamento, assim como a eficiência energética do Cynodon dactylon (L.) Pers, em sistema intensivo de produção de leite, na região de Coronel Pacheco - MG, sendo utilizados dados coletados pela Embrapa Gado de Leite, em média de sete anos. Para o levantamento dos componentes da matriz, foram utilizados coeficientes energéticos preconizados por autores especializados. A energia direta, relativa aos insumos, teve maior participação que a indireta, sendo os percentuais encontrados de 94,69 e 5,31, respectivamente. O principal consumidor de energia indireta foi o trator, por acionar todos os equipamentos tratorizados, seguido do equipamento de irrigação. A eficiência energética, de 4,18 , foi considerada favorável, demonstrando sustentabilidade do agroecossistema. A maioria da energia direta utilizada foi derivada de petróleo, na forma de combustível. Houve, ainda, grande consumo de outro derivado de petróleo, o fertilizante, principalmente na forma de nitrogênio $(28,89 \%$ do total).

PALAVRAS-CHAVE: estruturas e equipamentos, eficiência energética, sustentabilidade da agricultura.

\section{ENERGY ANALYSIS IN Cynodon dactylon (L.) PERS HAY PRODUCTION}

ABSTRACT: The aim of this work was to characterize the energy consumption related to the introduction, development, hay processing and storage of Cynodon dactylon (L.) Pers allied to the analysis of the energetic efficiency. The data used in this project were collected from Embrapa Gado de Leite, localized in Coronel Pacheco, Minas Gerais, Brazil. The data were obtained from a seven year period of an intensive system of milk production. Energetic coefficients were used to generate the survey and several matrix components obtained from pertinent literature. The direct energy, related to the inputs, showed more efficient participation on the energetic matrix than the indirect energy and the percentages were 94.64 and 5.31, respectively. Farm tractor was the main indirect energy consumer, which is responsible for turning on all the equipments, followed by the irrigation system. The energetic efficiency presented by the whole system was 4.2 , being considered positive and demonstrating that the agriculture ecosystem is sustainable. Most of the direct energy employed in this system was oil derived on fuel form. There was, however, a great consume of another oil derived energy such as fertilizer, but mainly on the nitrogen form (28.89\% of the total employed energy).

KEYWORDS: structures and equipments, energy efficiency, sustainability of agriculture.

\footnotetext{
${ }^{1}$ Extraído da tese de doutorado do primeiro autor.

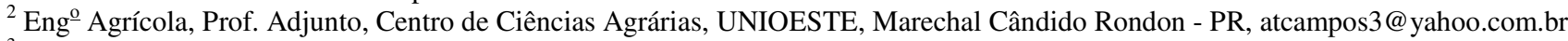

${ }^{3}$ Físico, Prof. Doutor, Faculdade de Ciências Agronômicas, UNESP - Câmpus de Botucatu - SP.

${ }^{4}$ Eng ${ }^{\mathrm{o}}$ Agrônomo, Pesquisador, Embrapa Gado de Leite, Juiz de Fora - MG

${ }^{5}$ Eng ${ }^{\circ}$ Agrônomo, Prof. Doutor, Faculdade de Ciências Agronômicas, UNESP - Câmpus de Botucatu - SP.

Recebido pelo Conselho Editorial em: 12-5-2004

Aprovado pelo Conselho Editorial em: 10-8-2005
} 


\section{INTRODUÇÃO}

O "coast-cross" (Cynodon dactylon (L.) Pers) é um dos volumosos mais utilizados em Cuba e no sudeste dos Estados Unidos, nas formas de pastejo e feno. HERRERA (1983) informou que o Cynodon dactylon (L.) Pers é uma gramínea que se adaptou às condições de clima tropical e subtropical, apresentando como características forrageiras desejáveis, na produção de feno, elevada massa seca por unidade de área e alto valor nutritivo. No Brasil, ele tem sido utilizado como feno ou in natura no campo, como parte da dieta em sistemas de produção de leite (VILELA \& ALVIM, 1996).

Embora a fenação se constitua um processo importante para o desenvolvimento da pecuária nacional, as forrageiras existentes, em geral, não atendem completamente às necessidades e ao equilíbrio alimentar do rebanho, sendo importante uma suplementação. A falta de tradição concorre para a resistência do pecuarista em adotar o feno como reserva forrageira, situação que, entretanto, tende a mudar, na medida em que o grau de aperfeiçoamento técnico dos agricultores é incrementado. Nesse âmbito, a fenação ocupa papel importante no manejo das pastagens, permitindo o aproveitamento dos excedentes de forragem em períodos de crescimento acelerado de forrageiras, visto que alterações na quantidade de animais por unidade de área são geralmente difíceis de serem realizadas (EVANGELISTA \& ROCHA, 1995).

Dos debates estabelecidos nos últimos anos sobre a questão energética no Brasil, pouca importância se deu ao balanço energético dos sistemas produtivos. Considerações maiores têm sido efetuadas na busca por novas fontes, a partir de culturas com alto potencial de produção calórica. $\mathrm{O}$ conhecimento da relação produção/consumo de energia, tanto quanto a análise econômica, é instrumental básico para elaboração de políticas que definam a quantidade de calorias e proteínas no consumo interno, exportação ou na transformação em combustíveis, permitindo prever o nível de dependência do País nessa área (CARMO et al., 1988; CARMO \& COMITRE, 1991).

O balanço energético visa a estabelecer os fluxos de energia, identificando sua demanda total e eficiência, refletida pelo ganho líquido de energia e pela relação saída/entrada, além da quantidade necessária para produzir ou processar um quilograma de determinado produto. Nesse processo, quantificam-se todos os insumos utilizados e produzidos que são transformados em unidades de energia. A determinação da eficiência energética é importante instrumento no monitoramento da sustentabilidade da agricultura ante o uso de fontes de energia não-renováveis (HETZ (1994) citado por SIQUEIRA et al., 1999; BUENO et al., 2000).

A importância da análise da eficiência energética é fornecer os parâmetros necessários para mensurar, interpretar e subsidiar a tomada de decisões no direcionamento das políticas tecnológicas (COMITRE, 1993).

Nesse contexto, a eficiência energética pode constituir-se numa interessante ferramenta indicadora de sustentabilidade para analisar a produção do feno do Cynodon dactylon (L.) Pers.

Neste trabalho, teve-se o objetivo de estimar a eficiência energética relativa à produção de feno a partir de Cynodon dactylon (L.) Pers, em um sistema intensivo de produção de leite.

\section{MATERIAL E MÉTODOS}

Foram utilizados dados coletados em sete anos de produção de feno de Cynodon dactylon (L.) Pers, do sistema intensivo de produção de leite (SIPL), da Embrapa Gado de Leite, em Coronel Pacheco - MG. A confecção da matriz energética iniciou-se pela definição do agrossistema e área, caracterizando-se o período enfocado, detalhando-se, em seguida, o itinerário técnico percorrido, sendo elaboradas, a seguir, as chamadas rubricas operacionais. Os itens que compuseram a matriz de exigência física da cultura foram transformados em coeficientes energéticos (BUENO et al., 2000). O sistema foi delimitado de forma a englobar as atividades relativas à produção, fenação e 
armazenamento do Cynodon dactylon (L.) Pers, incluindo todos os processos e gastos energéticos embutidos na atividade. O desempenho do sistema foi dado pela relação (CARVALHO, 1980) Produção Utilizada pelo Homem / "Inputs" Energéticos não-Gratuitos. Neste trabalho, a "Produção utilizada pelo homem" é equivalente àquela energia disponível no alimento volumoso, em forma de fardos de feno a serem fornecidos aos animais.

Como energia indireta, considerou-se aquela empregada na fabricação de equipamentos, construções e instalações, irrigação e outros "inputs" necessários à produção (CLEVELAND, 1995). Para o cálculo, foi utilizada metodologia específica desenvolvida por DOERING III et al. (1977), para quantificar os "inputs" de energia indireta utilizadas no sistema delimitado, por meio da depreciação energética, segundo os dias de utilização e em função da vida útil dos equipamentos. Como energia direta, foram considerados: combustíveis fósseis, lubrificantes, fertilizantes e calcário, micronutrientes, herbicidas, diretamente consumidos no sistema agrícola (BONNY, 1993).

A produção do feno pelo SIPL foi realizada seguindo as recomendações técnicas adequadas ao desenvolvimento da cultura, realizando as atividades da mesma maneira que em uma propriedade comercial. Foram utilizadas duas áreas: Área I com 3,0 ha, e a Área II com 12,0 ha.

No controle das plantas daninhas perenes, utilizou-se herbicida, à base de glyphosate, com dosagem de $4 \mathrm{~L} \mathrm{ha}^{-1}$, em operação tratorizada, com pulverizador de barra, antes da aração.

Para a correção do solo, após análise, distribuiu-se, a lanço de $2,5 \mathrm{t} \mathrm{ha}^{-1}$ de calcário dolomítico, visando a obter elevação da saturação de bases até o nível de $60 \%$. O calcário dolomítico foi incorporado ao solo, durante a aração, à profundidade de 0,25 a 0,30 m.

No preparo do solo, efetuou-se uma aração, com máquina de quatro discos fixos, que incorporou tanto os resíduos das plantas que sofreram a ação do herbicida, quanto o calcário lançado, seguindo-se de duas gradagens de nivelamento, destorroando o solo e inibindo o desenvolvimento de plantas daninhas. A adubação foi realizada a lanço, manualmente, aplicando-se $110 \mathrm{~kg}$ de $\mathrm{P}_{2} \mathrm{O}_{5}$ por hectare.

Com arado reversível de três discos, foram feitos sulcos de $0,15 \mathrm{~m}$ de profundidade, espaçados de 0,60 m, para a distribuição das mudas maduras e livres de invasoras, à taxa de 2,5 $\mathrm{tha}^{-1}$. As mudas, colocadas manualmente nos sulcos, em molhos de três a quatro estolhos, foram cobertas por meio da terra lançada pelos discos do arado, em sua passagem para a abertura do sulco adjacente.

Foram realizados seis a sete cortes por ano, por meio de segadora. Após o corte, a forragem foi mantida no local, sendo espalhada, enleirada e revolvida com ancinho, facilitando a secagem e recolhimento. Seco, o material foi recolhido e enfardado mecanicamente e transportado ao galpão de armazenamento, pronto a ser oferecido aos animais. Nesse ponto, encerrou-se o limite do sistema.

\section{Coeficientes energéticos/conversão energética}

Trabalho humano: Considerou-se a energia advinda dos funcionários efetivamente utilizada na produção de feno, ponderada pela carga horária dedicada a essa atividade, por meio do coeficiente energético de 386,40 $\mathrm{kJ} \mathrm{h}^{-1}$ de trabalho (CARVALHO et al., 1974).

Instalações: A composição energética do galpão de armazenamento de feno foi estimada por meio dos coeficientes energéticos de seus diversos constituintes (FERNANDES \& SOUZA, 1982; CAMPOS et al., 2003).

Insumos: Os valores energéticos dos elementos foram obtidos, via de regra, por meio da multiplicação de sua massa $(\mathrm{kg})$ ou volume (L) pelo conteúdo energético específico correspondente, apresentado pela bibliografia, ponderando seu nível de utilização por hectare, na cultura.

Fertilizantes e corretivos: Os valores adotados para os elementos são os informados por PELLIZZI (1992): $\mathrm{N}=73 \mathrm{MJ} \mathrm{kg}^{-1} ; \mathrm{P}_{2} \mathrm{O}_{5}=13 \mathrm{MJ} \mathrm{kg}^{-1} ; \mathrm{K}_{2} \mathrm{O}=9 \mathrm{MJ} \mathrm{kg}^{-1}$. Multiplicaram-se as 
quantidades efetivas dos elementos ativos $\left(\mathrm{N}, \mathrm{P}_{2} \mathrm{O}_{5}\right.$ e $\mathrm{K}_{2} \mathrm{O}$, em $\mathrm{kg}$ ) pelo valor energético correspondente. Para os micronutrientes, foi adotada a metodologia de determinação do coeficiente energético baseada na intensidade energética do produto nacional bruto, em $\mathrm{kJ}$ por valor monetário, preconizada por HEICHEL (1980). A energia contida no calcário foi obtida a partir da relação proposta por MACEDÔNIO \& PICCHIONI (1985), que considera o valor energético embutido no produto e o consumo de energia no transporte: $(40.938+228 \mathrm{~d}) 4,18410^{-3}\left(\mathrm{~kJ} \mathrm{~kg}^{-1}\right)$; sendo d a distância percorrida, em km. O coeficiente energético calculado para o calcário foi de $229 \mathrm{~kJ} \mathrm{~kg}^{-1}$.

Herbicidas: os coeficientes energéticos são informados por CLEMENTS et al. (1995), considerando, ainda, energia adicional de $20 \mathrm{MJ}$ por $\mathrm{kg}$ de ingrediente ativo, necessária para a formulação do herbicida (Green (1987) citado por CLEMENTS et al., 1995). O teor de ingrediente ativo é informado por LACA-BUENDIA et al. (1985).

Máquinas e equipamentos: Utilizou-se da metodologia desenvolvida por DOERING III et al. (1977), empregada por diversos autores (SERRA et al., 1979; ULBANERE, 1988; BEBER, 1989; COMITRE, 1993; CAMPOS et al., 2004; entre outros), baseada na depreciação energética que, a partir da massa das máquinas, consiste em depreciá-las durante sua vida útil. Os coeficientes adotados foram (MACEDÔNIO \& PICCHIONI, 1985): Equipamentos autopropulsionados, como tratores = $69,83 \mathrm{MJ} \mathrm{kg}^{-1}$; para os outros equipamentos $=57,20 \mathrm{MJ} \mathrm{kg}^{-1}$. O custo energético adotado para a fabricação do pulverizador costal foi de $72 \mathrm{MJ} \mathrm{kg}^{-1}$ (BANSAL et al., 1988).

Irrigação: O consumo energético para o funcionamento dos equipamentos é de $92 \mathrm{~kJ} \mathrm{~h}^{-1} \mathrm{~m}^{-1}$, e 2,40 $\mathrm{MJ} \mathrm{h}^{-1}$ para o bombeamento (TSATSARELIS, 1993).

Combustíveis e lubrificantes: Óleo diesel, óleo lubrificante e graxa, com poderes caloríficos de $38.535 \mathrm{~kJ} \mathrm{~L}^{-1}, 38.516 \mathrm{~kJ} \mathrm{~L}^{-1}$ e $43.179 \mathrm{~kJ} \mathrm{~kg}^{-1}$, respectivamente. Os coeficientes energéticos desses produtos, na mesma ordem, são de: $43.930 \mathrm{~kJ} \mathrm{~L}^{-1}, 43.908 \mathrm{~kJ} \mathrm{~L}^{-1}$ e $49.224 \mathrm{~kJ} \mathrm{~kg}^{-1}$ (SERRA et al., 1979).

\section{RESULTADOS E DISCUSSÃO}

A produção anual de feno de Cynodon dactylon (L.) Pers variou de 24 a 30 t ha $^{-1}$, com $85 \%$ de matéria seca, o que representa 20 a $25 \mathrm{t}$ de matéria seca $\mathrm{ha}^{-1}$ ano $^{-1}$. FERNANDEZ et al. (1983), por exemplo, variando o nível de nitrogênio na produção de Cynodon dactylon (L.) Pers, obtiveram produtividade de 24,4 $\mathrm{t} \mathrm{ha}^{-1} \mathrm{ano}^{-1}$. As áreas I e II produziram, em média, $4.240 \mathrm{~kg} \mathrm{ha}^{-1}$ de feno em cada corte.

A energia estimada para as máquinas e equipamentos agrícolas, transformada em demanda específica de energia, encontra-se na Tabela 1.

Agrupou-se o consumo de energia das máquinas, equipamentos e instalações, componentes da energia indireta para a produção de feno em um hectare, por ano (Tabela 2). Como se pode observar na Tabela 2, o trator apresentou consumo de energia indireta muito maior que os demais equipamentos, o que é coerente, uma vez que todos os equipamentos agrícolas foram acoplados a ele. Apesar de sua elevada utilização na fase de implantação da forrageira, depois de realizado o rateio, para os sete anos de vida considerados para a cultura, o trator teve seu consumo de energia indireta aplicado nessa fase reduzido a $60.773 \mathrm{~kJ} \mathrm{ha}^{-1}$ ano $^{-1}$ (Tabela 2), o que corresponde a 3,06\% de todo seu consumo de energia indireta.

$\mathrm{Na}$ manutenção anual da cultura, a participação do trator no consumo de energia indireta foi menor ainda (2,06\% do total), uma vez que foi utilizado somente para transportes. Contudo, o grande dispêndio de energia indireta dessa máquina se localiza na fase de fenação, na qual, por ser totalmente mecanizada, a operação é completamente dependente da utilização dos equipamentos responsáveis pelo corte, revolvimento e enfardamento, que são acoplados ao trator. Como consequiência, dos $71,56 \%$ de consumo relativo da energia indireta do trator, $94,88 \%$ se localiza na operação de fenação. 
TABELA 1. Massa, vida útil e demanda específica de energia (DEE) estimadas para as máquinas e implementos utilizados.

\begin{tabular}{lcrc}
\hline Discriminação dos Equipamentos & $\begin{array}{c}\text { Massa } \\
(\mathrm{kg})\end{array}$ & $\begin{array}{c}\text { Vida Útil } \\
(\mathrm{h})\end{array}$ & $\begin{array}{c}\text { DEE } \\
\left(\mathrm{MJ} \mathrm{h}^{-1}\right)\end{array}$ \\
\hline Trator agrícola de 55 kW $(75 \mathrm{cv})$ & 3.951 & 10.800 & 25,55 \\
Arado de 4 discos fixos de 28” & 1.200 & 3.000 & 22,88 \\
Arado de 3 discos reversíveis & 635 & 3.750 & 9,69 \\
Pulverizador de barra de 400 L & 195 & 1.200 & 9,30 \\
Grade niveladora & 515 & 4.500 & 6,55 \\
Carreta agrícola de madeira $\left(6 \mathrm{~m}^{3}\right)$ & 584 & 5.600 & 5,97 \\
Distribuidor de calcário & 280 & 2.250 & 7,12 \\
Segadora & 365 & 3.600 & 5,80 \\
Equipamento de irrigação & 2.100 & 15.000 & 8,01 \\
Pulverizador costal & 8 & 1.000 & 0,58 \\
Ancinho enleirador & 370 & 6750 & 3,14 \\
Enfardadora & 980 & 6750 & 8,30 \\
\hline
\end{tabular}

TABELA 2. Composição da energia indireta aplicada em equipamentos e estruturas.

\begin{tabular}{|c|c|c|c|c|}
\hline \multirow{2}{*}{ Equipamento } & \multicolumn{3}{|c|}{$\begin{array}{l}\text { Participação como Energia Indireta nas Fases } \\
\qquad\left(\mathrm{kJ} \mathrm{ha}^{-1} \text { ano }^{-1}\right)\end{array}$} & \multirow{2}{*}{$\begin{array}{c}\text { Total } \\
\left(\mathrm{kJ} \mathrm{ha}^{-1} \mathrm{ano}^{-1}\right)\end{array}$} \\
\hline & $\begin{array}{l}\text { Implantação da } \\
\text { Cultura }\end{array}$ & $\begin{array}{l}\text { Manutenção } \\
\text { Anual }\end{array}$ & Fenação & \\
\hline Trator & 60.773 & 40.880 & 1.885 .590 & 1.987 .243 \\
\hline Arado de 4 discos fixos de $28^{\prime \prime}$ & 8.433 & & & 8.433 \\
\hline Arado de 3 discos reversíveis & 6.921 & & & 6.921 \\
\hline Pulverizador de barra & 797 & & & 797 \\
\hline Grade niveladora & 2.358 & & & 2.358 \\
\hline Carreta agrícola de madeira & 2.772 & 9.552 & 104.475 & 116.799 \\
\hline Distribuidor de calcário & 1.221 & & & 1.221 \\
\hline Segadora & 1.243 & & 81.200 & 82.443 \\
\hline Equipamento de irrigação & 8.582 & 240.300 & & 248.882 \\
\hline Pulverizador costal & 663 & 4.640 & & 5.303 \\
\hline Ancinho enleirador & & & 73.476 & 73.476 \\
\hline Enfardadora & & & 156.870 & 156.870 \\
\hline Galpão de armazenamento & & & 86.106 & 86.106 \\
\hline
\end{tabular}

A enfardadora e o ancinho enleirador, que tiveram seu uso restrito à fase de fenação, assim como a segadora, que teve $98,49 \%$ de seu consumo energético indireto empregado, também na fenação, apresentaram participações na energia indireta total maiores que os arados, ou a grade, que são tradicionais consumidores de energia.

O galpão de feno participou com 3,10\% do consumo de energia indireta. Por ter vida útil de 40 anos, considerados ininterruptos, o galpão apresentou demanda específica de energia altamente diluída. O equipamento de irrigação, apesar de apresentar reduzidos consumos de energia direta, apresentou participação mais expressiva na energia indireta, ou seja, $8,96 \%$.

$\mathrm{Na}$ Tabela 3, apresentam-se as entradas de energia, nas formas direta e indireta e a eficiência, considerando-se os valores médios utilizados para cálculo de produção anual para um hectare da cultura. 
O maior consumo de energia no sistema em estudo correspondeu ao combustível, na forma de óleo diesel, com 58,73\% do total (Figura 1). Esse fato se explica pela intensiva utilização de equipamentos tratorizados na fase de fenação da cultura, que ocorreu cerca de sete vezes por ano. Dados os problemas relativos ao custo de energia e sua esgotabilidade, e considerando a crise energética que é atualmente vivenciada, o elevado consumo de energia na forma de combustível torna o item o principal "estrangulador" do presente sistema em estudo. As soluções visando à redução de consumo energético dentro dessa rubrica são complicadas, uma vez que estariam todas vinculadas à necessidade de redução de utilização de equipamentos para fenação.

As sugestões em que se pode fundamentar para a redução sensível do consumo de combustível, estão relacionadas à mudança de paradigma processual da operação de fenação, envolvendo maior utilização de mão-de-obra (trabalho humano - que apresentou reduzido consumo anual de energia Tabela 3) e maior dependência de fatores climáticos.

De toda a energia gasta na adubação (17.863 $\mathrm{MJ} \mathrm{ha}^{-1} \mathrm{ano}^{-1}$ ), 84,65\% foram empregados em $\mathrm{N}$, que possui elevado coeficiente energético, o que onera seu consumo. $\mathrm{O}_{2} \mathrm{O}_{5}$ teve participação no consumo energético muito menor que a do $\mathrm{N}$ e até do $\mathrm{K}_{2} \mathrm{O}$. Sua participação, mais expressiva, se efetivou durante a fase de implantação do Cynodon dactylon (L.) Pers que, para a análise energética final, teve seu valor distribuído pelos sete anos de utilização da cultura.

TABELA 3. Consumo de energia e eficiência na produção de feno a partir da cultura do Cynodon dactylon (L.) Pers no SIPL/Embrapa Gado de Leite.

\begin{tabular}{lc}
\hline Fonte de Consumo (“inputs”) & $\begin{array}{c}\text { Consumo de Energia } \\
\mathrm{MJ} \mathrm{ha}^{-1} \text { ano }^{-1}\end{array}$ \\
\hline Energias Indiretas & 1.987 \\
Trator & 455 \\
Equipamentos & 86 \\
Construções e Instalações & 249 \\
Equipamento de Irrigação & $\mathbf{2 . 7 7 7}$ \\
Subtotal - Energia Indireta & \\
\hline Energias Diretas & 15.121 \\
$\mathrm{~N}$ & 878 \\
$\mathrm{P}_{2} \mathrm{O}_{5}$ & 1.864 \\
$\mathrm{~K}_{2} \mathrm{O}$ & 82 \\
Calcário & 30.751 \\
Óleo Diesel & 389 \\
Óleo Lubrificante & 73 \\
Graxa & 75 \\
Irrigação & 0,5 \\
Herbicidas & 239 \\
Mudas & 93 \\
Mão-de-obra & $\mathbf{4 9 . 5 6 5}$ \\
Subtotal - Energia Direta & $\mathbf{5 2 . 3 4 2}$ \\
Total (a) & 224.134 \\
Energia efetiva contida no feno (b) & 4,3 \\
Eficiência energética (b $\div$ a) &
\end{tabular}

Em termos comparativos (Figura 1), os elevados consumos de combustível e fertilizantes tornam inexpressivas as participações de itens como a irrigação, mão-de-obra, mudas e construções que têm papel primordial na exploração em estudo, tornando evidente a maior eficiência desses itens e expondo 
a dependência da agricultura intensiva nos derivados de petróleo (tanto combustíveis, quanto fertilizantes).

De todo o montante energético investido na cultura, somente 5,31\% corresponde à energia indireta e 94,64\% são da categoria direta, demonstrando a elevada carga investida em insumos de uso direto na produção. Dentro da energia direta, cerca de $99 \%$ do consumo se caracteriza por insumos diretamente relacionados com petróleo (combustível, lubrificantes, fertilizantes e herbicidas) e 34,13\% da energia total é empregada na forma de fertilizantes derivados de petróleo, apresentando tendência semelhante aos trabalhos de BEBER (1989) e ULBANERE (1988).

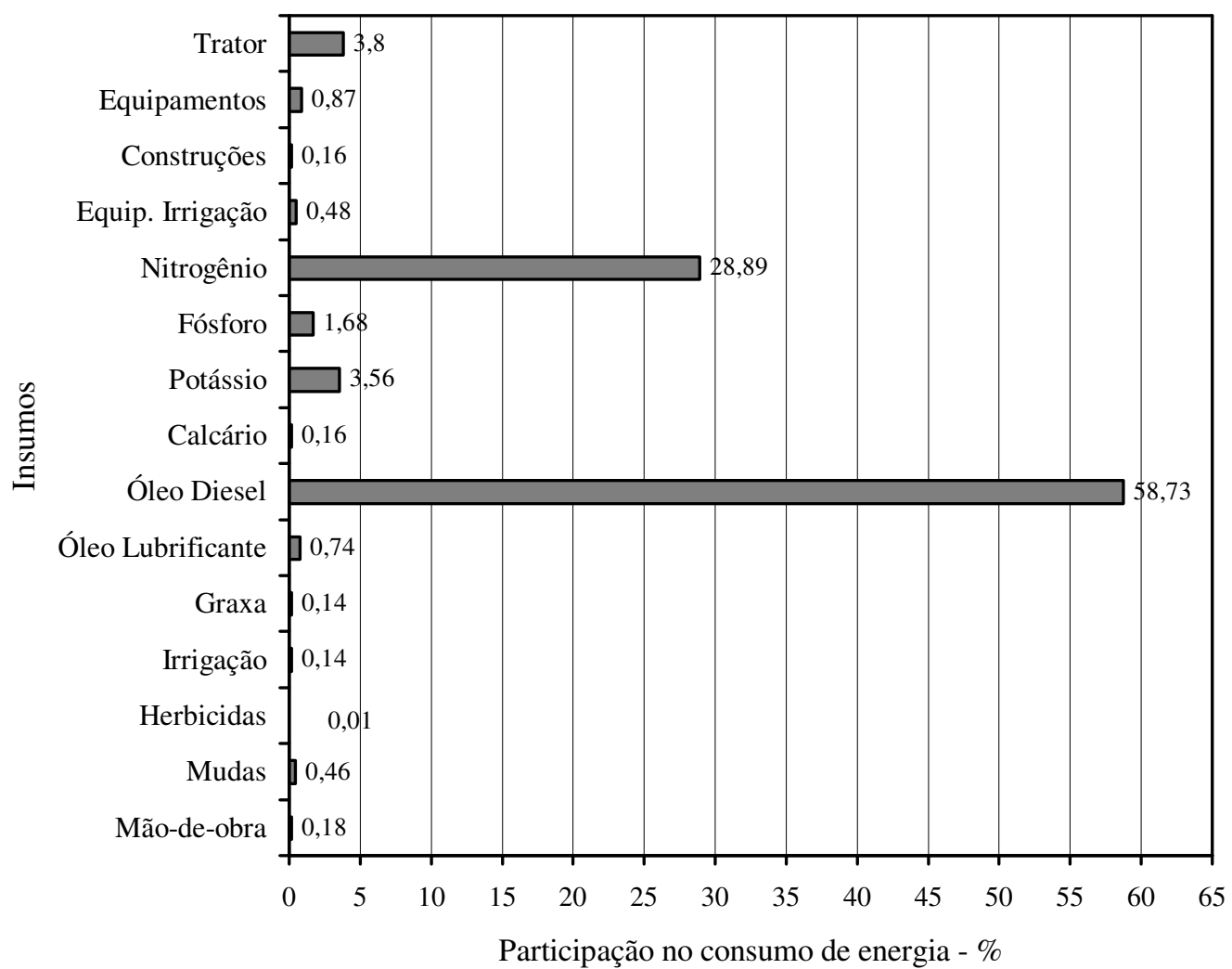

FIGURA 1. Participação percentual dos diversos insumos ("inputs") na formação da eficiência energética para a produção anual de feno de Cynodon dactylon (L.) Pers no SIPL/Embrapa Gado de Leite.

\section{Eficiência energética}

Como a produção de feno tem o objetivo de alimentação dos animais em produção, considerouse como energia convertida, inserida no feno de Cynodon dactylon (L.) Pers, aquela efetivamente utilizável pelo animal, assim como preconizam outros autores (CAMPOS, 2001; ZANINI et al., 2003; CAMPOS et al., 2004). A partir do valor médio de NDT (Nutrientes Digestíveis Totais) para o feno da cultura, obtido por estudos da Embrapa Gado de Leite, de $54 \%$ da matéria seca (média de $22.500 \mathrm{~kg}$ $\mathrm{ha}^{-1}$ ), ou seja, $12.150 \mathrm{~kg}$ de NDT por hectare, e, considerando o valor energético de $18.447 \mathrm{~kJ} \mathrm{~kg}^{-1} \mathrm{de}$ NDT, conclui-se que o total de energia embutida no Cynodon dactylon (L.) Pers produzido em um hectare por ano é de 224.134 MJ (Tabela 3). Sendo a energia despendida anualmente no processo produtivo de $52.342 \mathrm{MJ}$ por hectare, a eficiência energética na produção de feno é de 4,3. CAMPOS et al. (2004), trabalhando com alfafa, obtiveram eficiência energética para a produção do feno de 3,2. 
Apesar das intensas atividades com máquinas agrícolas tratorizadas e intensiva utilização de insumos energéticos, principalmente de derivados de petróleo, notadamente fertilizantes, a eficiência energética para a produção do feno de Cynodon dactylon (L.) Pers se mostrou bastante favorável. Em termos comparativos, de forma simplista, SCHROLL (1994), por exemplo, sugere que um índice de 2 para a relação saída/entrada de energia ("output"/“input”) seria razoável para uma política de desenvolvimento da sustentabilidade ecológica da Dinamarca.

A participação energética do combustível (Figura 1), nessa análise, superou os dados constantes na bibliografia para outras culturas, de forma geral. QUESADA et al. (1987) informam participações de 47,6\%; 46,5\% e 40,7\% na energia advinda do óleo diesel, para as culturas de milho, soja e trigo, respectivamente, em estudo desenvolvido no Rio Grande do Sul.

Em todas as etapas, houve baixo consumo de energia na forma de trabalho humano. Isso motiva autores, como ULBANERE (1988), a desconsiderar essa rubrica na contabilização dos consumos de energia. Neste trabalho, os valores baixos ocorreram devido às características da delimitação do sistema em estudo, que considera somente a mão-de-obra para as atividades de produção de feno.

\section{CONCLUSÕES}

Pode-se concluir que o trator teve o maior consumo de energia indireta, por acionar todos os equipamentos utilizados, e os de irrigação ocuparam o segundo lugar no consumo geral. Os equipamentos com maior demanda de energia indireta foram aqueles relacionados aos processos de fenação. A participação da energia indireta no processo foi de $5,31 \%$, a da direta foi de $94,69 \%$ e a eficiência energética foi de 4,3. Analisando globalmente o sistema, o maior consumo energético se deu na forma de combustível, seguido pelo nitrogênio, usado em fertilizantes, ambos derivados de petróleo.

\section{AGRADECIMENTOS}

À CAPES, pela concessão de bolsa de Doutorado.

\section{REFERÊNCIAS}

BANSAL, R.K.; KSHIRSAGAR, K.G.; SANGLE, R.D. Efficient utilization of energy with an improved farming system for selected semi-arid tropics. Agriculture, Ecosystems \& Environment, Amsterdam, v.24, n.4, p.381-394, 1988.

BEBER, J.A.C. Eficiência energética e processos de produção em pequenas propriedades rurais, Agudo - RS. 1989. 295 f. Dissertação (Mestrado em Extensão Rural) - Universidade Federal de Santa Maria, Santa Maria, 1989.

BONNY, S. Is agriculture using more and more energy ? A French case study. Agricultural Systems, Kidlington, v.43, n.1, p.51-66, 1993.

BUENO, O.C.; CAMPOS, A.T.; CAMPOS, A.T. Balanço de energia e contabilização da radiação global: simulação e comparativo. In: AVANCES en Ingeniería Agrícola. Buenos Aires: Editorial Facultad de Agronomia, 2000. p.477-82.

CAMPOS, A.T. Balanço energético relativo à produção de feno de "coast-cross" e alfafa em sistema intensivo de produção de leite. 2001. 236 f. Tese (Doutorado em Energia na Agricultura) - Faculdade de Ciências Agronômicas, Universidade Estadual Paulista, Botucatu, 2001.

CAMPOS, A.T.; SAGLIETTI, J.R.C.; BUENO, O.C.; CAMPOS, A.T.; KLOSOWSKI, E.S.;

GASPARINO, E. Balanço energético na produção de feno de alfafa em sistema intensivo de produção de leite. Ciência Rural, Santa Maria, v.34, n.1, p.245-51, 2004. 
CAMPOS, A.T.; SAGLIETTI, J.R.C.; CAMPOS, A.T.; BUENO, O.C.; GASPARINO, E.;

KLOSOWSKI, E.S. Custo energético de construção de uma instalação para armazenagem de feno. Ciência Rural, Santa Maria, v.33, n.4, p.667-72, 2003.

CARMO, M.S.; COMITRE, V. Evolução do balanço energético nas culturas de soja e milho no estado de São Paulo. In: CONGRESSO BRASILEIRO DE ECONOMIA E SOCIOLOGIA RURAL, 29., 1991, Campinas. Anais... Brasília: SBESR, 1991. p.131-49.

CARMO, M.S.; COMITRE, V.; DULLEY, R.D. Balanço energético de sistemas de produção na agricultura alternativa. Agricultura em São Paulo, São Paulo, v.35, n.1, p.87-97, 1988.

CARVALHO, A. Análise ecoenergética dos sistemas de produção agrícola da zona vitícola de Dois Portos (Torres Vedras). Lisboa: Fundação Calouste Gulbenkian, 1980. 44 p.

CARVALHO, A.; GONÇALVES, G.G.; RIBEIRO, J.J.C. Necessidades energéticas de trabalhadores rurais e agricultores na sub-região vitícola de Torres. Lisboa: Fund. Calouste Gulbenkian, 1974. 79 p.

CLEMENTS, D.R.; WEISE, S.F.; BROWN, R.; STONEHOUSE, D.P.; HUME, D.J.; SWANTON, C.J. Energy analysis of tillage and herbicide inputs in alternative weed management systems. Agriculture, Ecosystems and Environment, Amsterdam, v.52, n.2-3, p.119-28, 1995.

CLEVELAND, C.J. The direct and indirect use of fossil fuels and electricity in USA agriculture, 19101990. Agriculture, Ecosystems and Environment, Amsterdam, v.55, n.2, p.111-21, 1995.

COMITRE, V. Avaliação energética e aspectos econômicos da filière soja na região de Ribeirão Preto - SP. 1993. 152 f. Dissertação (Mestrado em Planejamento Agropecuário) - Universidade Estadual de Campinas, Campinas, 1993.

DOERING III, O.C.; CONSIDINE, T.J.; HARLING, C.E. Accouting for tillage equipment and other machinery in agricultural energy analysis. West Lafayette: Purdue University, 1977. 4 p. (Agr. Exp. Sta. NSF/RA - 770128).

EVANGELISTA, A.R.; ROCHA, G.P. Produção e utilização do feno. Lavras: Coordenadoria de Extensão, 1995. 18 p. (Circular Técnica, 35)

FERNANDEZ, D.; GOMEZ, L.; PARETAS, J.J. Fertilización nitrogenada em bermuda cruzada n.1 (Cynodon dactylon) sobre suelo pardo tropical. Ciência y Técnica en la Agricultura, Pastos y Forrages, La Habana, v.6, n.1, p.45-52, 1983.

FERNANDES, M.P.; SOUZA, A.M.T. Balanço energético - o consumo de energia na construção civil. Revista Brasileira de Tecnologia, Brasília, v.13, n.3, p.22-36, jun./jul. 1982.

HEICHEL, G.H. Assessing the fossil energy costs of propagating agricultural crops. In: PIMENTEL, D. Handbook of energy utilization in agriculture. Boca Raton: CRC Press, 1980. p.27-33.

HERRERA, R.S. La calidad de los pastos. In: INSTITUTO DE CIENCIA ANIMAL. Los Pastos en Cuba. La Habana: Instituto de Ciência Animal, 1983. v.2, p.59-115.

LACA-BUENDIA, J.P.; SILVEIRA FILHO, A.; VICTÓRIA FILHO, R.; MASCARENHAS, M.H.T.; SILVA, J.B.; GAZZIERO, D.L.P.; SOUZA, I.F; PEREIRA, R.C.; SILVA, J.F; FERREIRA, L.R.; COELHO, J.P. Herbicidas recomendados para as principiais culturas do Estado de Minas Gerais. Informe Agropecuário, Belo Horizonte, v.11, n.127, p.32-65, jul. 1985.

MACEDÔNIO, A.C.; PICCHIONI, S.A. Metodologia para o cálculo do consumo de energia fóssil no processo de produção agropecuária. Curitiba: Secretaria de Estado da Agricultura, 1985. v.1, 95 p.

PELLIZZI, G. Use of energy and labour in Italian agriculture. Journal of Agricultural Engineering Research, Silsoe, v.52, n.2, p.111-9, 1992. 
QUESADA, G.M.; BEBER, J.A.C.; SOUZA, S.P. de. Balanços energéticos: uma proposta metodológica para o Rio Grande do Sul. Ciência e Cultura, São Paulo, v.39, n.1, p.20-8, jan. 1987.

SCHROLL, H. Energy-flow and ecological sustainability in Danish agriculture. Agriculture, Ecosystems and Environment, Amsterdam, v.51, n.3, p.301-10, 1994.

SERRA, G.; HEEZEN, A.M.; MOREIRA, J.R.; GOLDEMBERG, J. Avaliação da energia investida na fase agrícola de algumas culturas. Brasília: Secretaria de Tecnologia Industrial, 1979. 86 p.

SIQUEIRA, R.; GAMERO, C.A.; BOLLER, W. Balanço de energia na implantação e manejo de plantas de cobertura do solo. Engenharia Agrícola, Jaboticabal, v.19, n.1, p.80-9, 1999.

TSATSARELIS, C.A. Energy inputs and outputs for soft winter wheat production in Greece. Agriculture, Ecosystems and Environment, Amsterdam, v.43, n.2, p.109-18, 1993.

ULBANERE, R.C. Análise dos balanços energético e econômico relativa à produção e perda de grãos de milho no Estado de São Paulo. 1988. 127 f. Tese (Doutorado em Energia na Agricultura) Faculdade de Ciências Agronômicas, Universidade Estadual Paulista, Botucatu, 1988.

VILELA, D.; ALVIM, M.J. Produção de leite em pastagem de Cynodon dactylon (L.) Pers., cv. "coast-cross". In: WORKSHOP SOBRE O POTENCIAL FORRAGEIRO DO GÊNERO CYNODON, 1., 1996, Juiz de Fora. Anais... Juiz de Fora: EMBRAPA-CNPGL, 1996. p.77-91.

ZANINI, A.; CAMPOS, A.T.; PRESTES, T.M.V.; DALMOLIN, M.F.S.; CAMPOS, A.T.

KLOSOWSKI, E.S. Análise energética na produção de silagem de milho. Acta Scientiarum, Maringá, v.25, n.2, p.105-11, 2003. 